\section{The Effects of Plastic Mulch Systems on Soil Temperature and Moisture in Central Ontario}

\author{
Kayla Snyder ${ }^{1}$, Amanda Grant ${ }^{2}$, Christopher Murray $^{3,5}$, \\ and Bryon Wolff ${ }^{4}$
}

ADDITIONAL INDEX WORDS. plasticulture, microclimate stabilization, moisture retention

SUMMARY. The impact of polyolefin-based agricultural mulch films (including clear, black, and white-on-black films) on soil temperature and moisture content was studied, using a bare plot as a control, over a 4-month period in central Ontario, Canada. Data indicate a negative correlation between the change in soil temperature under the films relative to bare soil and the absolute value of bare soil temperature. Additionally, a negative correlation between the effect of films on soil moisture and the moisture level of bare soil was indicated. All mulch films demonstrated qualitatively similar ability to insulate the soil from extremes in both temperature and moisture, suggesting a potentially reduced need for irrigation and protecting against early frost, high temperatures, overwatering, and drought.

$\mathrm{M}$ ulching is a process by which crops of interest are protected from environmental exposure and competition from weeds by covering or surrounding desirable plants with material that forms a barrier to light and moisture (Kasirajan and Ngouajio, 2012). Mulch consists of a thin layer that may be organic material (such as wood chips, grass clippings, straw, or other lowvalue biproducts of agriculture), textile, or films of metal or plastic. Plastic mulch films can be of synthetic or biological origin, or a combination of the two types of materials (Kyrikou et al., 2011). Plastics such as polyethylene have been used as agricultural mulch in many parts of the world for more than 50 years (Espí et al., 2006; Lamont, 1993, 2005).

The use of mulch films can be viewed as a positive step toward a more sustainable model of large-scale agriculture in a number of ways. First, soil erosion is greatly limited by the use of these films, as rain cannot fall directly onto soil, and wind cannot carry it away (Scarascia-Mugnozza et al., 2004). Second, the use of mulch films dramatically reduces the requirement

\footnotetext{
${ }^{1}$ Department of Chemistry, Lakehead University, Orillia, ON

${ }^{2}$ Department of Biology, Lakehead University, Orillia, $\mathrm{ON}$

${ }^{3}$ Department of Sustainability Sciences, Lakehead University, 500 University Avenue, Orillia, ON

${ }^{4}$ Polymer Specialties International, Ltd., New market, ON

${ }^{5}$ Corresponding author. E-mail: cmurrayl@ lakeheadu.ca.
}

for irrigation because evapotranspiration is reduced (Ramalan and Nwokeocha, 2000). Third, through the addition of pigments such as carbon black to otherwise transparent or translucent polymers, mulch films can partially or completely block sunlight and thus prevent any plants from growing that are not planted in holes punched or cut in the films. In this way, the use of agricultural mulch film reduces competition for soil nutrients without the use of herbicides (Greer and Dole, 2003 ).

The benefits of using mulch films are offset by costs associated with their purchase, application, removal, and disposal (Lamont, 1993). As a result, their use is not common in many regions in North America. A survey completed in 2010 noted that only $2 \%$ of farmers in Ontario, Canada, are using mulch films (Black Sheep Strategy, 2011). Mulch film use is much more prevalent in Europe, where restrictions on the use of pesticides, herbicides, and genetically modified crops are, in general, more severe than in North America. Considering growing public concern about these agricultural practices (both from a safety and sustainability point of view), there is good reason to examine the feasibility of their use in North American climates.

In spite of a great deal of research having been conducted on the effects of mulch composition (Greer and Dole, 2003) and color (Decoteau et al., 1990; Díaz-Pérez and Batal, 2002; Greer and Dole, 2003; Lamont, 1993) on soil temperature (Chakraborty et al., 2008; Díaz-Pérez, 2009, 2010; Díaz-Pérez et al., 2005; Lamont, 2005), moisture (Chakraborty et al., 2008; Greer and Dole, 2003; Ramalan and Nwokeocha, 2000), and plant yields (Bolton and Aylesworth, 1973; Brault et al., 2002; Chakraborty et al., 2008; Csizinszky et al., 1995; Díaz-Pérez, 2009, 2010; Díaz-Pérez and Batal, 2002; DíazPérez et al., 2004, 2005; Greer and Dole, 2003; Maurya and Lal, 1981; Ramalan and Nwokeocha, 2000; Spizewski et al., 2010), there remains uncertainty associated with the mechanism by which mulch films achieve their beneficial effects. As previously noted by Díaz-Pérez in 2010, likely sources of uncertainty include convolution of the effects of mulch with that of different climates on crop yields, and the tendency of research to focus on plant yields rather than on environmental parameters such as root zone temperature (RZT). While work has been reported that attempts to clarify the effects of mulch by examining the same films over different seasons (DíazPérez, 2010), there remains a scarcity of reported work that focuses on the effect of mulch in cooler climates.

The effects of mulch films on soil temperature is generally regarded as the most important means by which the use of mulch impacts crop yield. Mulch films adjust the energy flow in soil (Liakatas et al., 1986; Rosenberg et al., 1983; Tarara, 2000), allowing different parts of the incident solar spectrum (depending on the type of film) to penetrate the film and reach

\begin{tabular}{llll}
\hline $\begin{array}{l}\text { Units } \\
\text { To convert U.S. to SI, } \\
\text { multiply by }\end{array}$ & U.S. unit & SI unit & $\begin{array}{l}\text { To convert SI to U.S., } \\
\text { multiply by }\end{array}$ \\
\hline 0.3048 & $\mathrm{ft}$ & $\mathrm{m}$ & 3.2808 \\
2.54 & inch(es) & $\mathrm{cm}$ & 0.3937 \\
25.4 & inch $(\mathrm{es})$ & $\mathrm{mm}$ & 0.0394 \\
0.0254 & mil & $\mathrm{mm}$ & 39.3701 \\
2.5900 & mile & $\mathrm{km}^{2}$ & 0.3861 \\
$\left({ }^{\circ} \mathrm{F}-32\right) \div 1.8$ & ${ }^{\circ} \mathrm{F}$ & ${ }^{\circ} \mathrm{C}$ & $\left({ }^{\circ} \mathrm{C} \times 1.8\right)+32$
\end{tabular}


the soil, preventing the loss of lower energy infrared radiation. While some reports of the effects on soil temperature indicate that the use of white and reflective films can lower the maximum temperature experienced by the soil, the most commonly reported effect (for black and clear films) is average temperature increases relative to bare soil temperature, enabling earlier germination and longer growing seasons. Increased growing degree days (Gosling et al., 2014) at the beginning of a season can improve likelihood of success for a farmer in a number of ways: it increases the choices of crops that can be grown (often those demanding a higher price require longer, warmer growing seasons); it enables crops to be grown with lower risk and greater likelihood of germination; and it affords the farmer more choice as to when plants may be harvested, potentially providing produce at times when price and demand are high. Alternatively, the warming effect of mulch films can be hazardous to plant growth, as temperatures damaging to the plant can be reached more easily during the hottest parts of the season (Díaz-Pérez, 2009, 2010; Díaz-Pérez and Batal, 2002; DíazPérez et al., 2005; Gordon et al., 2010). In colder climates (such as that experienced by many regions in central Ontario), risk of damage to plants by high temperatures is generally less of a concern than the risk of frost early in the growing season. Among the many studies that have been conducted examining the effect of mulch on soil temperature, the majority report similar results regarding the average effect of different types of film: transparent films provide the greatest warming of the soil by permitting most of the solar spectrum to penetrate the film and trapping the longer wavelength infrared radiation; white-on-black films and silver films block the greatest part of the spectrum, reflect a large portion back upwards toward the plants, and provide the least amount of warming, often leading to cooler temperatures than bare soil; and black films (the type most prevalently used) provide an intermediate effect between that of clear and white-on-black films, and generally increase the soil temperature by 3 to $5^{\circ} \mathrm{F}$ ( 1.7 to $\left.2.8^{\circ} \mathrm{C}\right)$ relative to bare soil (Ham et al., 1993;
Lamont, 1993). Agreement on the effect of mulch films in general and of the color of the mulch in particular is not unanimous. One study that was conducted in Mexico and examined double-cropping mulch films found that the average soil temperature beneath white-on-black mulch films was actually higher than that of bare soil (Ibarra-Jiménez et al., 2012). Another study noted that no significant change between the soil temperatures under black and clear mulch films was observed (Waterer, 2010). Yet another study showed that black mulch films had higher maximum soil temperatures than clear films (Ham et al., 1993).

There are several possible explanations for discrepancies between soil temperatures measured under nominally identical mulch films. One possible source of disagreement between reports of the effect of mulch films may be short measuring periods. Many published studies (Decoteau et al., 1990; Díaz-Pérez, 2010; Díaz-Pérez and Batal, 2002; Díaz-Pérez et al., 2004; Gordon et al., 2008, 2010) only report temperature measurements conducted over 1 or 2 weeks and extrapolate these results to the entire season. In central Ontario, for example, dramatic fluctuations in weather over any season make it necessary to perform measurements over much longer periods of time, as inference of an entire season's climate based on 1 week could lead to as much as $50 \%$ error in daily temperature or associated growing degree days (Environment Canada, 2014).

The general lack of soil moisture measurements to accompany measurements of soil temperature may constitute a further explanation of the different results obtained when measuring temperature under films of different color. Although it is known that mulch films reduce soil evapotranspiration and therefore affect the extent to which soil cools through evaporation (Al-Kayssi, 2002), there are few studies that carefully quantify the effect of mulch on soil moisture. Díaz-Pérez et al. (2004) noted that when using irrigation methods bare soil did not have as high water potential as soil covered with plastic mulch, such that less irrigation was required for mulch-covered soil. Similarly, Ramakrishna et al. (2006) observed higher levels of soil moisture under mulch films in Vietnam. Sanders et al.
(1986) noted that the use of mulch films leads to more consistent availability of moisture for vegetables. Plastic mulches have demonstrated ability in preventing flooding of crops (Bolton and Aylesworth, 1973), and thus can protect crops from either extreme moisture loss or gain. Not all studies have shown the same impact of mulch use on soil moisture, or a relationship between moisture and temperature: in 2010, Díaz-Pérez saw no correlation between soil water and RZT, nor any relationship between mulch film color and soil moisture. Since the high specific heat capacity of water will provide soil with high moisture greater resilience to temperature change than what one would expect in drier soil (Díaz-Pérez, 2010 ), it is especially intriguing that there is a lack of consistency in reported effects of mulch on soil temperature and moisture.

Another possible explanation for discrepancy may be a difference in the degree of soil/film contact from study to study. As noted by Ham et al. (1993), if the mulch films are placed loosely onto the soil, an insulating air gap develops, which causes either an increase in heat storage or a decrease in heat loss. Therefore, how the films are actually laid on the surface may strongly affect the results obtained. There is little attention paid to characterizing the degree to which mulch films are in contact with soil in most published reports, so elucidation of the impact of this factor is not straightforward.

Finally, another possible explanation of apparently discrepant results is the effect of different climates experienced by the different geographic locations where studies are conducted. As previously mentioned, this possibility has been identified by Díaz-Pérez (2010), who explored the effect of different climates by studying the same mulch-covered plots during different seasons. The difference in mean RZT measured in the fall and spring was never much more than $1^{\circ} \mathrm{C}$ for any of the different types of mulch tested. To continue to develop an improved understanding of the behavior of mulch films and how their impact on soil temperature depends on climate, it may be necessary to examine their effect when used in more varied climates, such as the generally cooler conditions experienced in Ontario. 
Central Ontario often experiences under 1000 growing degree days (measured over $10^{\circ} \mathrm{C}$ ) during the growing season (Environment Canada, 2014), and during the May to Sept. 2013 period represented in this study, 1560 growing degree days were recorded. The sites of previous studies of mulch films are typically warmer and the 2013 season was no exception: Tifton, GA (where several studies undertaken by Díaz-Pérez have been conducted), experienced over 3200 growing degree days (over $10^{\circ} \mathrm{C}$ ). Most other studies of the effects of mulch on soil temperature have been conducted at similar (Gordon et al., 2008, 2010; Kyrikou et al., 2011) or even warmer (Chakraborty et al., 2008) climates.

Several studies of the effects of mulch film have been conducted in southern Ontario, but none were concerned with the effects of mulch films on soil temperature, which must be known to elucidate the general behavior of these films (Díaz-Pérez, 2010). Studies that have taken place in Ontario have examined the use of mulch in flood management (Bolton and Aylesworth, 1973) or have focused on effects on the yield of specific crops (Wiebe, 1973; Zhang et al., 2007). The Orillia area has a climate typical of central Ontario, and historically experiences between 1750 and 2000 growing degree days, when measured above $5{ }^{\circ} \mathrm{C}$, or $\approx 1150$ when measured above $10{ }^{\circ} \mathrm{C}$ (Environment Canada, 2014). It is thus representative of more than 300,000 $\mathrm{km}^{2}$ in Canada (Government of Canada, 1995) and an order of magnitude more area in the northern regions of the United States. This climate is considered to be one that enables confident growth of field crops such as winter wheat (Triticum hybernum) and soybean (Glycine max) (Molenhuis, 2012), but a predictable increase in the growing season would enable the farming of generally higher-value field crops and vegetables. Given that mulch films' ability to extend the growing season is of critical importance to farmers in cooler climates, that greater contrast in the climate in which films are studied has been identified as a necessity in understanding the general behavior of these films, and considering the amount of arable land at stake, an examination of the potential benefits of mulch films in this climate is timely. The objectives of this research were to examine the effects of film color on the RZTs and soil moisture content in a cool climate. Comparison between the effects of black, white-on-black, and clear films on soil microclimate, and comparison of the effects of these films relative to uncovered soil were the foci of the experiments presented here.

\section{Materials and methods}

S I T E S E L E C T I O N A N D PREPARATION. A site on Lakehead University's Orillia campus grounds (lat. $44.593^{\circ} \mathrm{N}$, long. $79.459^{\circ} \mathrm{W}$ ) was chosen for its direct sunlight and distance from interferences such as the parking lot, walkways, or neighboring agricultural fields. An area of grass-covered soil was tilled using a small tractor/tiller on 29 Apr. 2013 , resulting in seven rows used for this study, each $\approx 1.5 \mathrm{~m}$ wide and $4 \mathrm{~m}$ long. At the same time rows were prepared, drip tape was placed $\approx 5 \mathrm{~cm}$ deep in the center of the row.

In six of the rows, polyethylenebased agricultural mulch film was laid onto the soil, with the outside $30 \mathrm{~cm}$ of each 1.5 -m-wide strip being buried by soil to prevent it from catching the wind. The films were laid over the soil in such a way as to emulate commercial practice, maintaining consistent tension in the films that was not so large as to lead to stretching but was large enough to ensure soil to film contact typical of that resulting from application by a commercial film laying machine. Films of thickness between 1 and 1.1 mil and three types of pigmentation were measured: clear, black, and white-on-black film with the white layer facing upwards. Though vegetable yield was not the focus of this study, to ensure that exposure to sunlight and other possible effects of plants were consistent with other studies, vegetables were planted using a split-plot design, with each of the six plots split into three sections of identically treated vegetables (the subplot factor): broccoli (Brassica oleracea), onion (Allium cepa), and carrot (Daucus carota). One of each of the three different mulch colors (the whole plot factor) was applied to each plot, allowing for two replicates. Each plot was otherwise treated identically, with equal irrigation, no soil amendments, and no weeding. A bare soil plot was used to compare soil temperature and moisture measurements.

M E A S U R E M E N T O F ENVIRONMENTAL AND SOIL PARAMETERS. Soil RZT was recorded daily (at 4:00 PM), Monday to Friday, using a soil thermometer (Rapitest model 1618; Lusterleaf, Woodstock, IL) inserted to a depth of 7 to $10 \mathrm{~cm}$. For the bare row and one of the rows covered by black film, a datalogging thermometer (model OM-EL-USBTC; Omega Engineering, Stamford, CT) was used to measure the soil temperature in the middle of the row. Measurements made using soil thermometers were repeated until less than $5 \%$ variation between three consecutive measurements was obtained, to account for any lag in the thermometers. Such measurements presented below are averages of three measurements after equilibrium was achieved. Measurements by the datalogger were recorded every $30 \mathrm{~min}$ at a depth of 7 to $10 \mathrm{~cm}$.

Moisture levels were recorded daily at about 4:00 PM, Monday to Friday, using a soil moisture meter (Rapitest model 1820, Lusterleaf). Before the study began, halfway through the study and at the end of the study, the moisture meter was calibrated by comparing its measurements with soil samples for which moisture content was determined gravimetrically by measuring the soil before and after drying in an oven. At the beginning of the season temperature and moisture measurements were made at 8:00 $\mathrm{AM}, 12: 00 \mathrm{PM}$, and 4:00 PM to confirm that daily measurements were sufficient to demonstrate the difference between the temperature and moisture of the rows.

Measurements of irrigation volume, rainfall, and other environmental parameters [including wind speed, wind direction, ultraviolet index, and relative humidity] were recorded and verified based on results obtained from a nearby weather station.

\section{Results and discussion}

Qualitative observations. Impact of the mulch films on moisture retention was immediately evident as condensation could be observed through the clear films (and felt under the opaque films). 
As the season progressed, it was also evident that the opaque films completely eliminated weed growth, except in a small area surrounding the plants where the mulch film had been cut away to allow planting. Weeds could be observed through the clear films and while certainly present throughout the season, they did not grow to a point where they were competing for sunlight with the vegetables of interest.

EFFect of MULCH FILMS ON TEMPERATURE. Daily measurements of RZT showed that the temperatures under the clear films were often higher than that of the uncovered plot, temperatures under the whiteon-black films were most often lower, and temperatures under the black films were often closer to those measured in uncovered soil (Fig. 1). These average results were consistent with what had been previously reported for the effects of similar mulch in warmer climates (Chakraborty, 2008; Díaz-Pérez, 2009, 2010; DíazPérez and Batal, 2002; Díaz-Pérez et al., 2005; Gordon et al., 2008, 2010; Streck et al., 1995), but further investigation of the detailed effects over the entire season demonstrated several differences from previously reported results. The overall effect of the mulch film on temperature is most apparent when the difference between the RZT of the mulchcovered rows and that of the uncovered row is shown as a function of the uncovered soil temperature (Fig. $2)$. Though there is typically a $4^{\circ} \mathrm{C}$ variation in the magnitude of this difference of RZT for any given uncovered soil temperature, there is still a clear negative correlation $(P \leq$ 0.001 ) between this difference in RZT and the bare soil temperature: for all films, when the bare soil temperature increases, the difference between bare soil RZT and that measured beneath the films decreases, such that at the lowest ambient temperatures the warming effect on RZT under the films is greatest (i.e., the increase in temperature is greatest) and when ambient temperatures are higher, the RZT under the films shows the films warm the least or may even cool the underlying soil. Additionally, there is a difference between the effects of the three types. While each type of film similarly has an insulating effect on the soil it

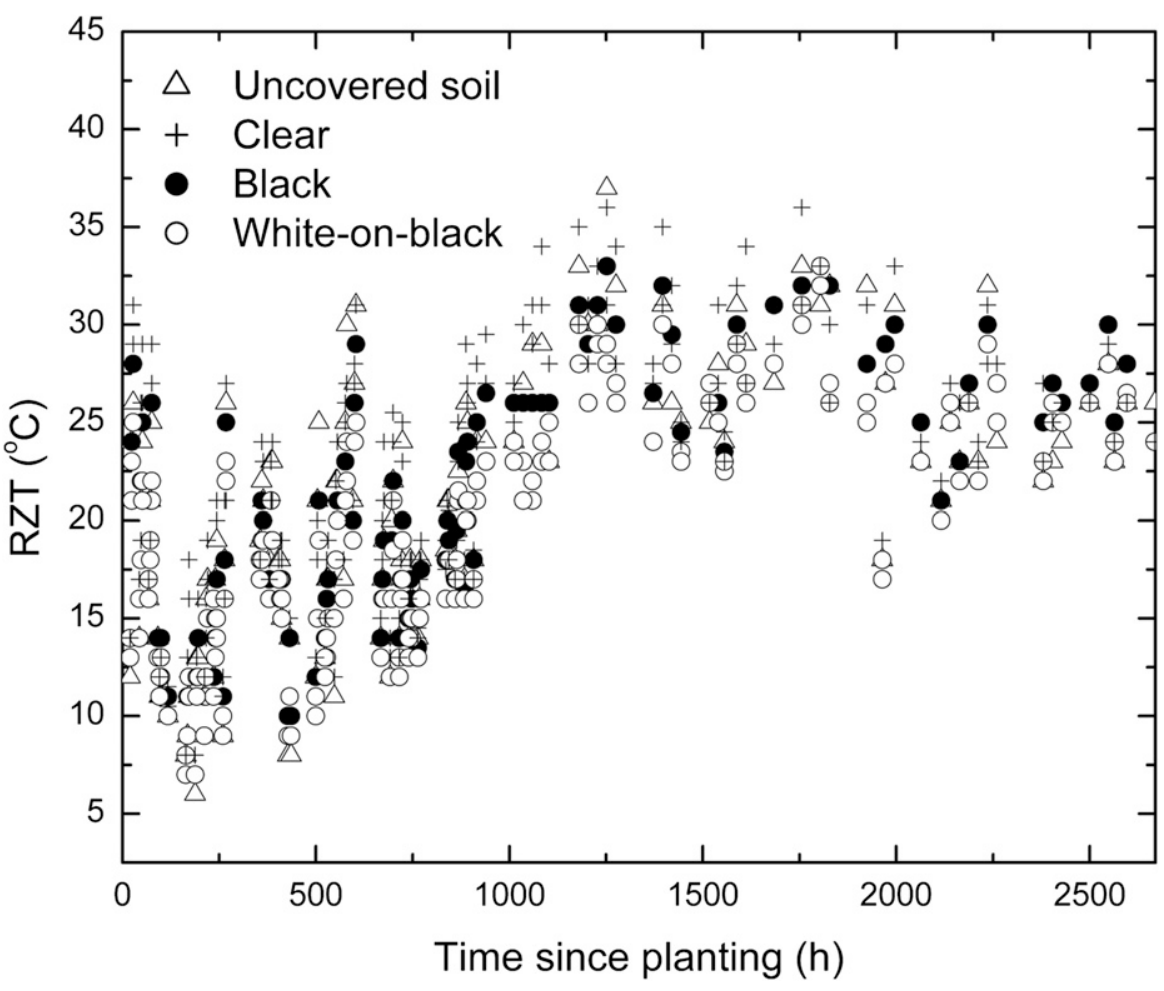

Fig. 1. Daily measurements of root zone temperature (RZT) in test plots, as a function of time. Measurements for the uncovered soil (open triangles), soil covered with clear mulch film (crosses), black film (closed squares) and white-onblack film (open squares) are shown for the $107 \mathrm{~d}$ of the project. The areas under the curves are 62931 degree hours (for bare soil), 61598 degree hours (for soil covered by black film), 65186 degree hours (for soil covered by clear film), and $\mathbf{5 8 7 9 3}$ degree hours (for soil covered by white-on-black film); $\left(1.8 \times{ }^{\circ} \mathrm{C}\right)+32={ }^{\circ} \mathrm{F}$.

covers (rather than simply one of warming), the sets of data are offset from each other, as indicated by simple linear fits in Fig. 2. Though the variation in difference in RZT measured at any particular bare soil temperature is high and larger than the absolute difference between the linear fits to the data for different treatments, there is still clearly a systematic difference between the effects of the three films, and one that is consistent with previously reported measurements of these films. Clear films, on average, lead to warmer values of RTZ, and white-on-black films lead to the lowest values of RZT. Black films provide an effect intermediate between the clear and white-on-black treatments. This general trend has been observed previously, but the similar negative correlation between the film effects on RZT and bare soil temperatures has not been emphasized in the literature. While the clear films lead to the highest temperatures, on average, they do not simply warm the soil as most reports summarize. Rather, their behavior is better described as insulative, providing warmer RZT when bare soil is coolest and less warming when bare soil temperature is highest. The effect of black and white-on-black film on RZT is qualitatively similar, but values of RZT achieved are systematically lower: white films provide the least amount of warming when bare soil temperatures are low (relative to the effect of the other colors of film) and decrease RZT when bare soil is the warmest. The effect of the black films appears to be intermediate between that of the clear and white-on-black films: moderate warming is observed when temperatures are low and lower temperatures are achieved (relative to the bare soil) when temperatures are high. Possible explanations for observed insulation rather than overall warming could be trapped air between the soil and film which limits transfer of heat, or increased moisture that acted to mediate temperature change. That each row had a consistent soil density and film tension would suggest that the amount of trapped air would be similar and would perhaps support such 
a mechanism yielding qualitatively similar results. As is shown below, as all films acted to stabilize the moisture content of the soil they covered, it is perhaps not surprising that all films exhibited the same insulative capacity. Certainly, the different fractions of the electromagnetic spectrum permitted by the different films must play an important role and may explain why the different film treatments exhibit consistent difference in absolute value of soil temperature achieved. Simply considering the amount of light permitted by the different films cannot by itself account for clear films warming less when temperatures are warmest (and sunlight is correspondingly high), nor can such an explanation account for white-on-black films warming the soil at the coldest times of the growing season.

There are several notable similarities and differences between these results and what has been noted in the literature for similar films. It can be inferred from the work of DíazPérez (Díaz-Pérez, 2009; Díaz-Pérez et al., 2005 ) and Streck et al. (1995) that a similar insulating ability of mulch films has been observed in some cases since the most extreme temperatures (both highest and lowest) were often (though not always) found for bare soil. It is noteworthy that while the use of mulch films has been observed to result in reduced diurnal variation in RZT (Díaz-Pérez, 2009; Díaz-Pérez et al., 2005), this effect was most pronounced in cooler fall seasons (Díaz-Pérez, 2009). This does not seem to be as consistent an effect as in this study, however, as there are other instances where the soil temperature under the mulch film is increasingly higher than that of the bare soil (Díaz-Pérez and Batal, 2002; Díaz-Pérez et al., 2005; Gordon et al., 2010), a trend that is the reverse of what was noted in an Ontario climate.

Results for all measured plots for the entire season are shown in Figs. 1 and 2 . To confirm that data collected during the day was representative of the entire 24 -h period, data of greater detail, but limited range was collected through the use of two thermometers equipped with dataloggers to measure the RZT under a black mulch film and in an uncovered plot for 11 $\mathrm{d}$ in June (Fig. 3). The data thus obtained confirm the long-term,

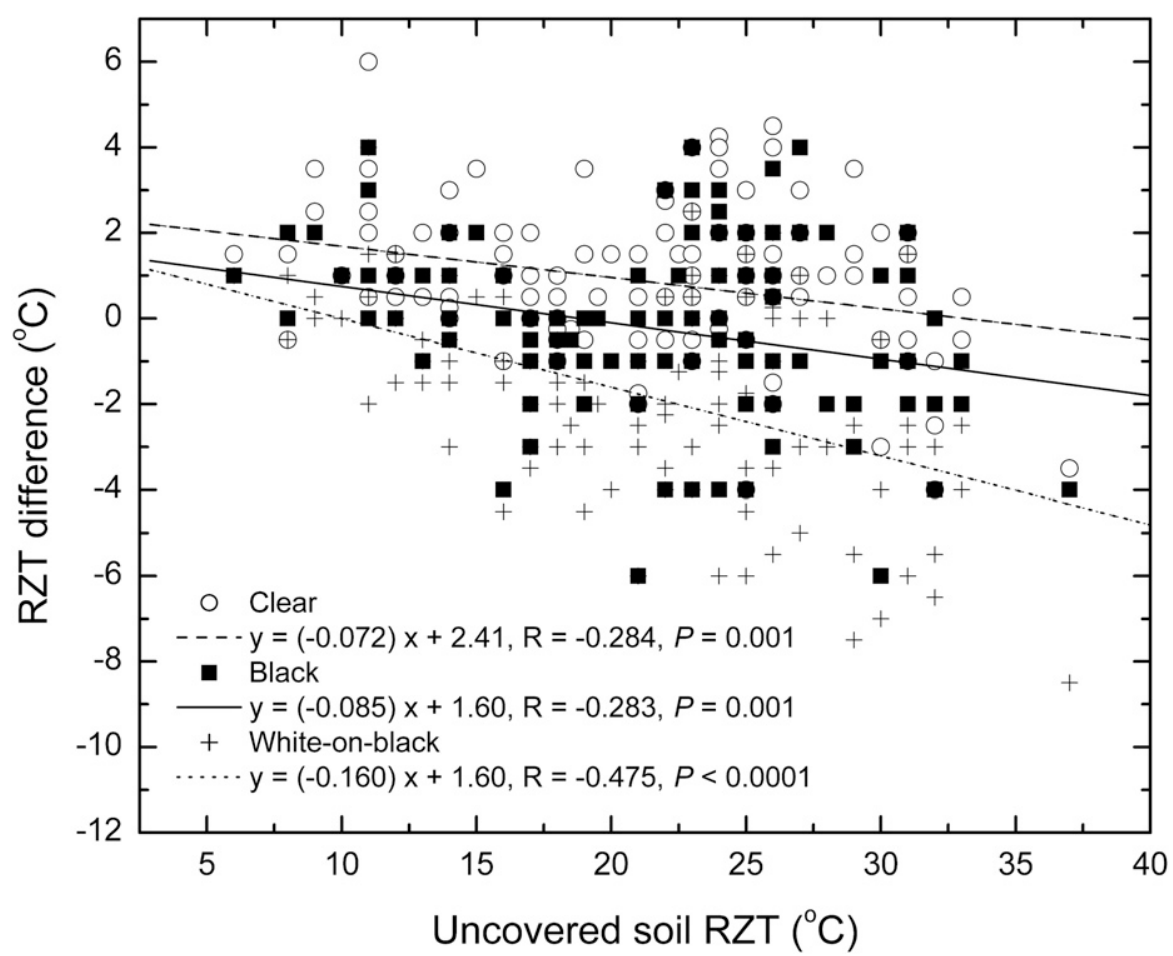

Fig. 2. Difference between measured root zone temperature (RZT) under each type of mulch film and the RZT measured for the uncovered soil, as a function of the uncovered soil temperature; $\left(1.8 \times{ }^{\circ} \mathrm{C}\right)+32={ }^{\circ} \mathrm{F}$.

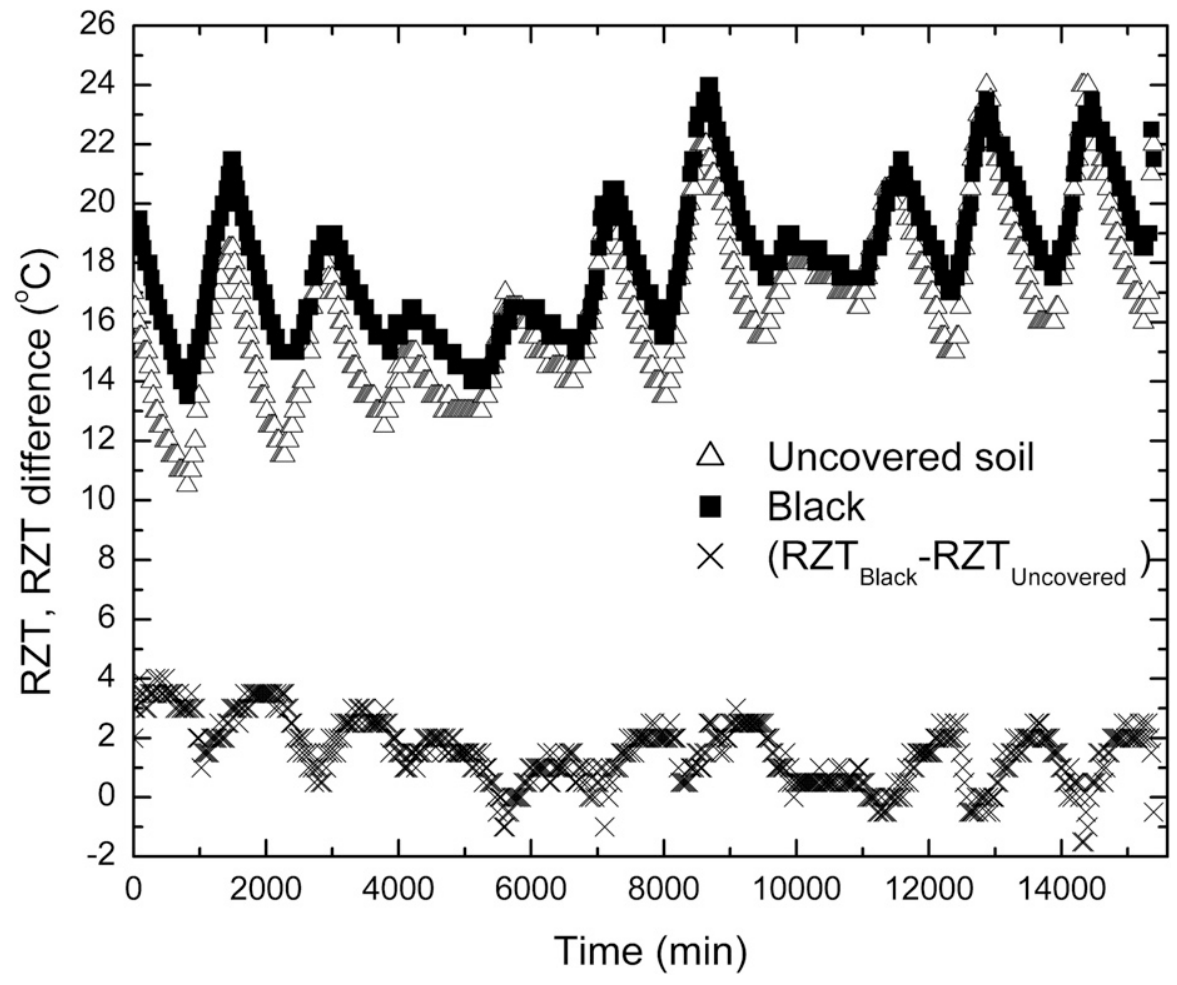

Fig. 3. Root zone temperature (RZT) measured using a thermocouple equipped with datalogger for a plot covered by black mulch film (closed squares) and an uncovered plot (open triangles), and the difference between the two, indicating warmer temperatures under the black film (by $1.5^{\circ} \mathrm{C}$ on average). Time zero is $3: 45$ PM on 3 June $2013 ;\left(1.8 \times{ }^{\circ} \mathrm{C}\right)+32={ }^{\circ} \mathrm{F}$. 
daytime-only measurements described above and provide greater detail: not only are the maxima and minima in the uncovered soil temperature mediated by the presence of the film, but there is a lag of $\approx 3-4$ h between the temperature maxima/minima in the film-covered row relative to that in the bare row.

For the 1l-d period shown, there is an average increase in temperature of $\approx 1.5^{\circ} \mathrm{C}$ under the black film compared with the uncovered soil, consistent with what has been reported elsewhere. It is clear that the temperature under the black film never gets as low as the lowest temperatures experienced by the bare soil, and that during the highest temperatures conditions under the black film are often the same as that of the bare soil or even of lower temperature. As temperature falls in the latter part of the day, the temperature under the film appears to lag behind that of the bare soil, the mulch becoming most effective at night when (even in June) the mulch film keeps the minimum temperature of the soil 2 to $3^{\circ} \mathrm{C}$ higher than that of the unprotected soil. As bare soil temperatures begin to climb again, they catch up and often exceed those of the soil under the film. When the temperature difference between rows is examined as a function of the uncovered soil temperature (Fig. 4), it confirms the trend shown in Fig. 2. Even over this narrow temperature range, the insulating effect of the mulch film is clear: less warming is provided during hotter periods and more warming takes place when the external temperature is low. As one might expect, inclusion of nighttime data makes the trend more pronounced (a steeper linear fit).

Because the influence of the films on soil temperature is not always warming but rather insulating, simply considering the effect of the mulch on soil growing degree days is not necessarily a useful indication of the beneficial effect the mulch has on soil temperature. When the whole season is considered, it may even be that the use of films results in decreased soil growing degree days because the soil under the films is protected from the hottest days in summer, when temperatures more greatly risk damage to the plants. It is at the beginning of the season, when low temperatures slow germination, that the effect of the

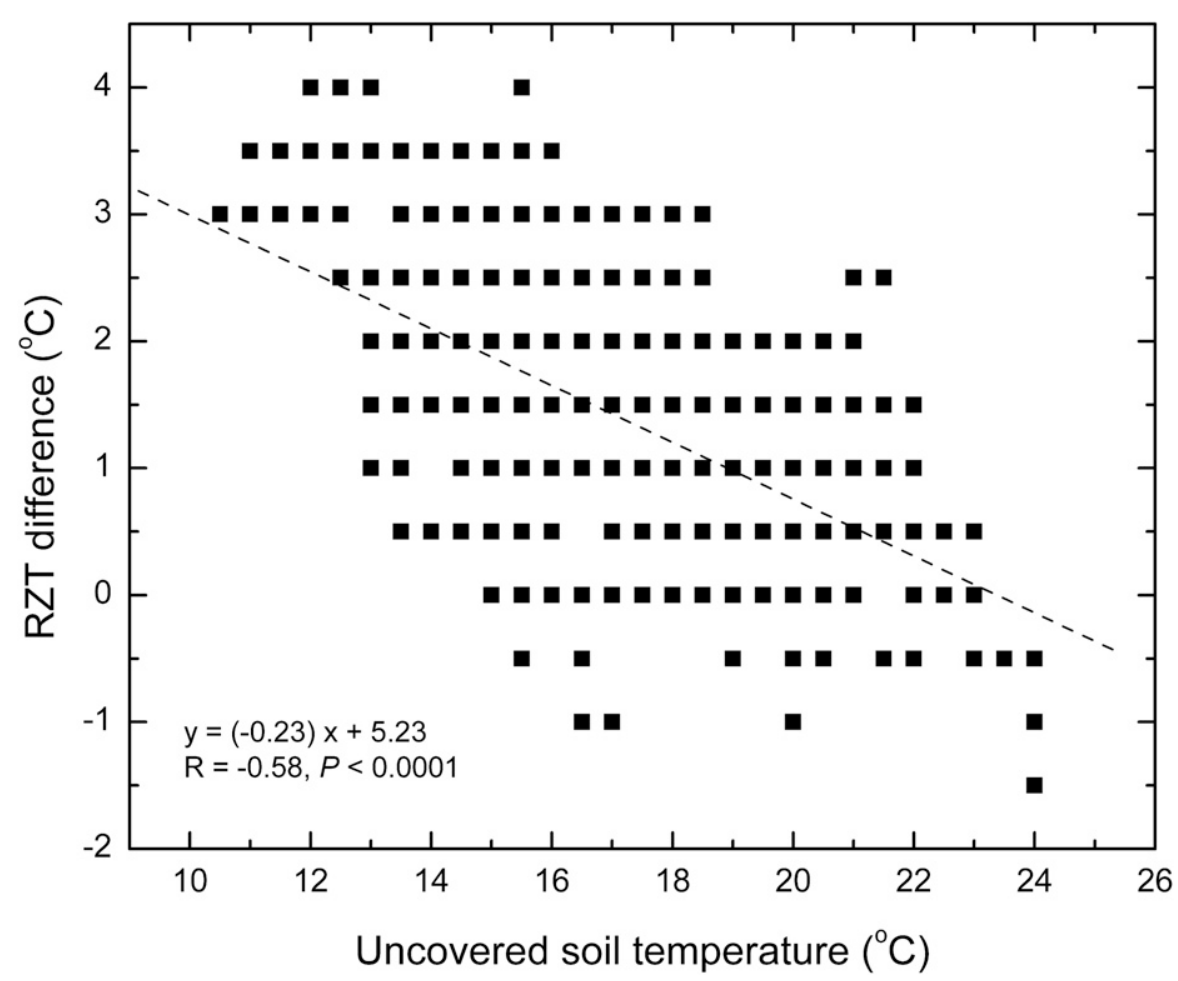

Fig. 4. Difference between root zone temperature (RZT) measured using a thermocouple equipped with datalogger for a plot covered by black mulch film and an uncovered plot (shown as a function of time in Fig. 3 ) as a function of uncovered soil $\mathrm{RZT} ;\left(1.8 \times{ }^{\circ} \mathrm{C}\right)+32={ }^{\circ} \mathrm{F}$.

mulch films is of greatest impact. A small increase in average temperature could easily correspond to a season that begins more than a week earlier. Considering the case of carrots (the only vegetable grown from seed in this study), an increase of average early-season temperature from 41 to $50{ }^{\circ} \mathrm{F}\left(5.0\right.$ to $\left.10.0{ }^{\circ} \mathrm{C}\right)$ can decrease the days required to germinate from $5 \mathrm{ld}$ to less than $20 \mathrm{~d}$ (Maynard and Hochmuth, 2007). This can allow farmers to grow crops that are more susceptible to early frost with greater confidence and allow them to tailor their planting so that harvest coincides with times of favorable demand for particular crops.

In contrast to the majority of results reported for warmer climates, when the uncovered soil temperature was high enough to prevent growth or even risk damage to the plants, the mulch films reduced that threat. In the rows covered by white-on-black films (which provided the least warming relative to the uncovered soil), the soil temperature was as much as $8{ }^{\circ} \mathrm{C}$ lower than in the uncovered soil at the hottest times of the season. For all the vegetables grown in this study, uncovered soil temperatures exceeded the maximum temperature tolerable for growth: 85,75 , and $75^{\circ} \mathrm{F}(29.4$, 23.9 , and $23.9^{\circ} \mathrm{C}$ ) for onion, broccoli, and carrots, respectively (Maynard and Hochmuth, 2007), and the soil under the mulch films (especially for the black and white-on-black films) spent much less time at or above those temperatures. Possible causes of this insulative effect could include trapped air or more stable soil moisture in filmcovered soil than bare soil (as is described below), and it is possible that different amounts of incident visible light experienced at different latitudes could explain why this behavior would be more noticeable in cool climates than in warmer ones.

Another possible explanation for a systematic dependence of soil temperature on mulch type is the indirect effect of enhanced plant growth. As the use of mulch is well known to increase plant growth relative to bare soil, it is reasonable to expect that larger plants will provide more shade to the mulch and affect the solar energy impinging on the mulch. In the study described here, the impact of plant growth on soil temperature cannot be quantified or separated from that of the mulch alone, but 
we can assume that it likely less than what might be experienced in other studies because of the type of plants grown and the measured vegetable yield for each mulch type. As onethird of each row was devoted to carrots, onions, and broccoli, only one-third of each row experienced significant shade. While broccoli is a large plant that will substantially shade the mulch surrounding it, because plants are typically grown only 45 to $60 \mathrm{~cm}$ apart, the amount of shadow it casts is not directly proportional to the plant size and quickly reaches a limit (after reaching a lateral extent of 20 to $30 \mathrm{~cm}$ ) after which further growth does not impact the amount of shadow cast. Additionally, though not a focus of this study, the vegetable yield for the different treatments was recorded (data not shown) and did not have a clear systematic dependence on mulch type. Average values of vegetable yield for soil covered by black films were below that of soil covered by clear or white-onblack films, and the difference between duplicate row yields was larger than the difference between average values for each treatment.

EFFECT OF MULCH FILMS ON SOIL MOISTURE. The effect of the mulch film on soil moisture was qualitatively similar to the observed effect on temperature, though there was not a noticeable dependence of effect on the type of film. As is demonstrated in Fig. 5, the general impact of the mulch film was to stabilize the soil moisture: when the uncovered plot was the driest, all mulch films maintained more than $5 \%$ higher moisture levels (on average) in the soil they covered. When the soil in the uncovered plot reached moisture levels of more than $35 \%$ (typically following rainfall) the mulch-covered plots were all drier: by $5 \%$ to $10 \%$, on average. Not only does this correspond to decreased requirements for irrigation, but by providing more stable moisture content, the mulch films prevented damage due to insufficient root aeration during the wettest conditions. While the mulch films divert overhead water from rain away from the soil and thus provide protection from overwatering, they also retain moisture otherwise lost through evapotranspiration, such that what might appear to be contradictory behavior arises. Both increased moisture relative to dry, bare

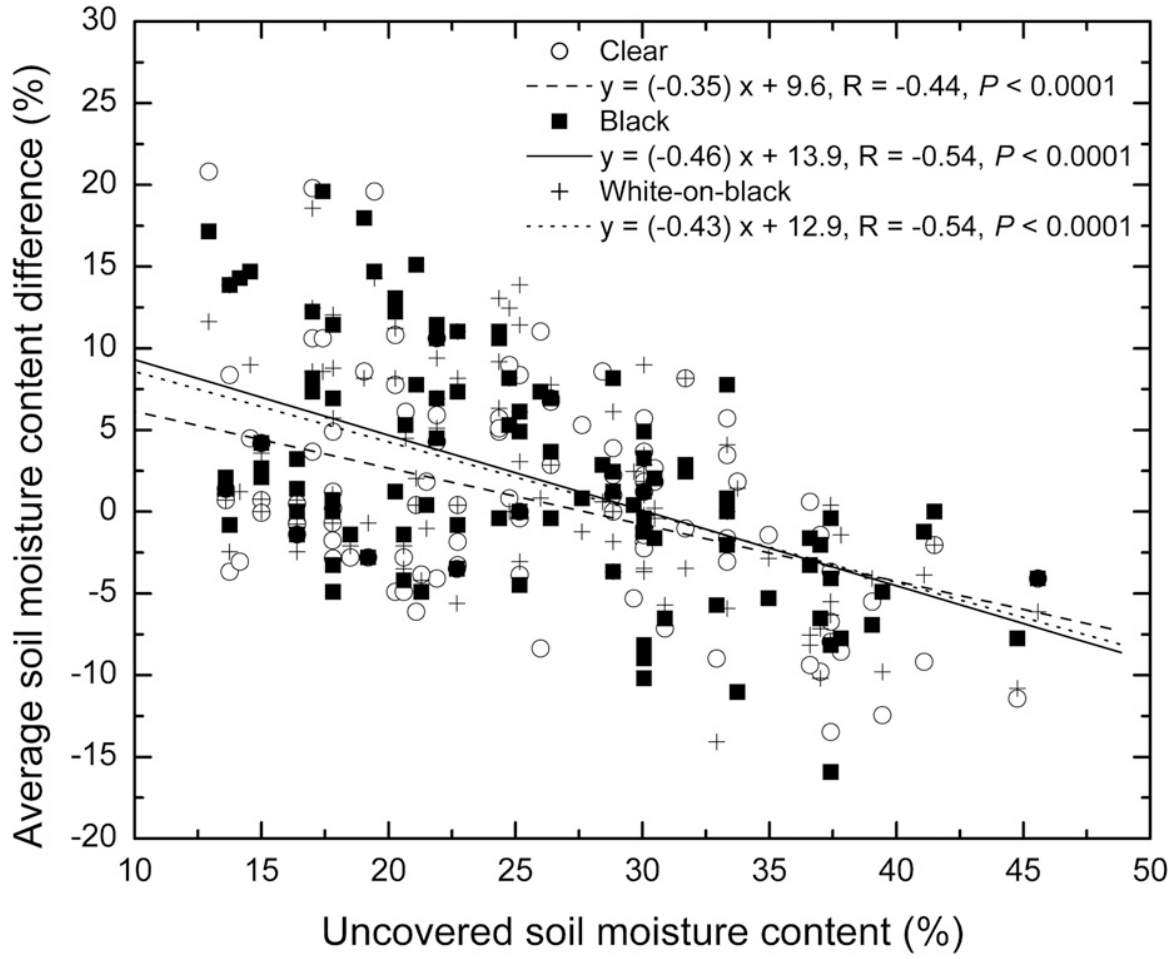

Fig. 5. Difference between average soil moisture content under clear (open circles), black (closed squares) and white (crosses) mulch films and the uncovered soil moisture content, as a function of uncovered soil moisture content.

soil and decreased moisture levels relative to uncovered soil overwatered by rain can be achieved through the use of the mulch film, and both of these phenomena are explained by the film's ability to restrict the transport of water.

The observed effects on soil moisture are noteworthy for at least two reasons: first, while this stabilizing effect on moisture is simple to explain based on the barrier to permeability imposed by the film, it has not been reported elsewhere. Second, the parallel between the insulative effect the mulch films have on soil temperature and the stabilizing effect films have on moisture has not been previously noted for similar mulch systems. While other studies have reported individual measurements consistent with this behavior, no other study we are aware of has measured such a clear relationship between soil moisture and temperature. It is reasonable to think that because of water's high heat capacity, maintaining a consistent level of moisture would provide an insulating effect similar to what is observed in this study. It is interesting, then, that this is either not commented on in other studies of the effects of very similar mulch films on temperature and moisture in warmer climates, or a contradictory effect is observed. Díaz-Pérez noted that while one would predict such behavior, there was no correlation between soil moisture level and RZT, nor a clear effect of film type (color) on soil moisture (Díaz-Pérez, 2010). This latter observation is understandable, but the former contributes to what he calls a "far from understood" effect of film color on soil moisture.

Very little irrigation was required during the test to maintain adequate soil moisture. Over the entire growing season, irrigation equivalent to 5 to $6 \mathrm{~mm}$ of precipitation was administered to each row, and all rows were irrigated at the same time. This volume of water is negligible when compared with the $330 \mathrm{~mm}$ of rainfall experienced by the area over the duration of the experiment.

There are several clear implications for farmers that may be derived from these results. Increased flexibility and the ability to grow with greater confidence may both be afforded by the different types of microclimate control that can be achieved through the use mulch films. In general, the films evaluated in this study provide insulation against extremes in temperature, 
and choosing films with different pigments can offer effects ranging from higher to lower average temperatures. Additionally, the use of mulch films reduced the requirement for irrigation or other forms of water management, as both extreme wet and dry conditions were mitigated by the protection of the films. Considering the dramatically increased level of control achieved through the use of these films, the general stabilizing effect they demonstrated on both soil moisture and temperature, and decreased dependence on resources such as water offered by the use of these films in this type of climate, further examination of their properties is warranted.

\section{Literature cited}

Al-Kayssi, A.W. 2002. Spatial variability of soil temperature under greenhouse conditions. Renew. Energy 27:453-462.

Black Sheep Strategy. 2011. Clean FARMS Ontario farmer survey, final report. 29 July 2013. <http://www.cleanfarms.ca/ resources? $\mathrm{q}=$ resources_ontario $>$.

Bolton, E.F. and J.W. Aylesworth. 1973. Use of black polyethylene mulch to reduce flooding effects on tomato yields. Can. J. Plant Sci. 53:857-861.

Brault, D., K.A. Stewart, and S. Jenni. 2002. Growth, development, and yield of head lettuce cultivated on paper and polyethylene mulch. HortScience 37:92-94.

Chakraborty, D., S. Nagarajan, P. Aggarwal, V.K. Gupta, R.K. Tomar, R.N. Garg, R.N. Sahoo, A. Sarkar, U.K. Chopra, K.S.S. Sarma, and N. Kalra. 2008. Effect of mulching on soil and plant water status, and the growth and yield of wheat (Triticum aestivum L.) in a semi-arid environment. Agr. Water Mgt. 95:1323-1334.

Csizinszky, A.A., D.J. Schuster, and J.B. Kring. 1995. Color mulches influence yield and insect pest populations in tomatoes. J. Amer. Soc. Hort. Sci. 120:778-784.

Decoteau, D.R., M.J. Kasperbauer, and P.G. Hunt. 1990. Bell pepper plant development over mulches of diverse colors. HortScience 25:460-462.

Díaz-Pérez, J.C. 2009. Root zone temperature, plant growth and yield of broccoli [Brassica oleracea (Plenck) Var. Italica] as affected by plastic film mulches. Sci. Hort. 123:156-163.

Díaz-Pérez, J.C. 2010. Bell pepper (Capsicum annum L.) grown on plastic film mulches: Effects on crop microenvironment, physiological attributes, and fruit yield. HortScience 45:1196-1204.
Díaz-Pérez, J.C. and K.D. Batal. 2002 Colored plastic film mulches affect tomato growth and yield via changes in root-zone temperature. J. Amer. Soc. Hort. Sci. 127:127-135.

Díaz-Pérez, J.C., S.C. Phatak, D. Giddings, D. Bertrand, and H.A. Mills. 2005. Root zone temperature, plant growth, and fruit yield of tomatillo as affected by plastic film mulch. HortScience 40:13121319.

Díaz-Pérez, J.C., W.M. Randle, G. Boyhan, R.W. Walcott, D. Giddings, D. Bertrand, H.F. Sanders, and R.D. Gitaitis. 2004. Effects of mulch and irrigation system on sweet onion: I. Bolting, plant growth, and bulb yield and quality. J. Amer. Soc. Hort. Sci. 129:218-224.

Environment Canada. 2014. Historical climate data - Environment Canada. 12 July 2014. <http://climate.weather.gc. ca/climateData/dailydata_e.html? Station ID $=42183 \&$ timeframe $=2 \&$ Ye ar $=2013 \&$ Month $=7 \& \mathrm{cmdBl}=$ Go\# $>$.

Espí, E., A. Salmerón, A. Fontecha, Y. García, and A.I. Real. 2006. Plastic films for agricultural applications. J. Plastic Film Sheeting 22:85-102.

Gordon, G.G., W.G. Foshee, S.T. Reed, J.E. Brown, and E.L. Vinson. 2010. The effects of colored plastic mulches and row covers on the growth and yield of okra. Hort Technology 20:224-233.

Gordon, G.G., W.G. Foshee, S.T. Reed, J.E. Brown, E. Vinson, and F.M. Woods. 2008. Plastic mulches and row covers on growth and production of summer squash. Intl. J. Veg. Sci. 14:322-338.

Gosling, S.N., E.K. Bryce, P.G. Dixon, K.M.A. Gabriel, E.Y. Gosling, J.M. Hanes, D.M. Hondula, L. Liang, P.A.B. Lean, S. Muthers, S.T. Nasximento, M. Petralli, J.K. Vanos, and E.R. Wanka. 2014. A glossary for biometeorology. Intl. J. Biometeorol. 58:277-308.

Government of Canada. 1995. Canada Growing degree days. 10 Sept. 2014. <http://geogratis.gc.ca/api/en/nrcanrncan/ess-sst/610cd0b8-4791-53748245- al2a053bcd4a.html>.

Greer, L. and J.M. Dole. 2003. Aluminum foil, aluminum-painted, plastic, and degradable mulches increase yields and decrease insect vectored viral diseases of vegetables. HortTechnology 13:276-284.

Ham, J.M., G.J. Kluitenberg, and W.J. Lamont. 1993. Optical properties of plastic mulches affect the field temperature regime. J. Amer. Soc. Hort. Sci. 1 18:188193.

Ibarra-Jiménez, L., L.A. Valdez-Aguilar, A. Cárdenas-Flores, H. Lira-Saldivar,
J. Lozano-del Río, and C.L. Cavazos. 2012. Influence of double cropping on growth and yield of dry beans with colored plastic mulches. Chilean J. Agr. Res. 72:470-475.

Kasirajan, S. and M. Ngouajio. 2012. Polyethylene and biodegradable mulches for agricultural applications: A review. Agron. Sustainable Dev. 32:501-529.

Kyrikou, I., D. Briassoulis, M. Hiskakis, and E. Babou. 2011. Analysis of photochemical degradation behaviour of polyethylene mulching film with pro-oxidants. Polym. Degrad. Stabil. 96:2237-2252.

Lamont, W.J. 1993. Plastic mulches for the production of vegetable crops. HortTechnology 3:35-39.

Lamont, W.J. 2005. Plastics: Modifying the microclimate for the production of vegetable crops. HortTechnology 15: $477-481$.

Liakatas, A., J.A. Clark, and J.L. Monteith. 1986. Measurements of the heat balance under plastic mulches. Part I. Radiation balance and soil heat flux. Agr. For. Meteorol. 36:227-239.

Maurya, P.R. and R. Lal. 1981. Effects of different mulch materials on soil properties and on the root growth and yield of maize (Zea mays) and cowpea (Vigna unguiculata). Field Crops Res. 4:33-45.

Maynard, D.N. and G.J. Hochmuth. 2007. Knott's handbook for vegetable growers. Wiley, Hoboken, NJ.

Molenhuis, J. 2012. Budgeting tools. 15 June 2014. <http://www.omafra.gov.on. $\mathrm{ca}$ /english/busdev/bear2000/Budgets/ budgettools.htm\#vegetables\%20\%20For\% 20Review\%20Only>.

Ramakrishna, A., H.M. Tam, S.P. Wani, and T.D. Long. 2006. Effect of mulch on soil temperature, moisture, weed infestation and yield of groundnut in northern Vietnam. Field Crops Res. 95:115-125.

Ramalan, A.A. and C.U. Nwokeocha. 2000. Effects of furrow irrigation methods, mulching and soil water suction on the growth, yield and water use efficiency of tomato in the Nigerian Savanna. Agr. Water Mgt. 45:317-330.

Rosenberg, N.J., B.L. Blad, and S.B. Verma. 1983. Microclimate: The biological environment. Wiley, New York, NY.

Sanders, D.C., T.R. Konsler, W.J. Lamont, and E.A. Estes. 1986. Pepper and muskmelon economics when grown with plastic mulch and trickle irrigation. Proc. Natl. Agr. Plastics Congr. 19:302314.

Scarascia-Mugnozza, G., E. Schettini, and G. Vox. 2004. Effects of solar radiation on 


\section{Research Reports}

the radiometric properties of biodegradable films for agricultural applications. Biosystems Eng. 87:479-487.

Spizewski, T., B. Fraszczak, A. Kaluzewicz, W. Krzesinski, and J. Lisiecka. 2010. The effect of black polyethylene mulch on yield of field-grown cucumber. Acta Scientiarum Polonorum/Hortorum Cultus 9: 221-229.
Streck, N.A., F.M. Schneider, G.A. Buriol, and A.B. Heldwein. 1995. Effect of polyethylene mulches on soil temperature and tomato yield in plastic greenhouse. Scientia Agricola 52:587-593.

Tarara, J.M. 2000. Microclimate modification with plastic mulch. HortScience 35:169-180.

Waterer, D. 2010. Evaluation of biodegradable mulches for production of warm-season vegetable crops. Can. J. Plant Sci. 90:737-743.

Wiebe, J. 1973. Tunnel covers and mulches for muskmelon production. Can. J. Plant Sci. 53:157-160.

Zhang, T.Q., C.S. Tan, and J. Warner. 2007. Fresh market sweet corn production with clear and wavelength selective soil mulch films. Can. J. Plant Sci. 87:559-564. 